\title{
ROLE OF LEISURE AMONG THE SOLIGAS OF BILIGIRI RANGANA BETTA (B.R. HILLS), KARNATAKA
}

S.Saraswathi, ${ }^{*}$ R. Raju, ${ }^{* *}$ K.N. Baidya***

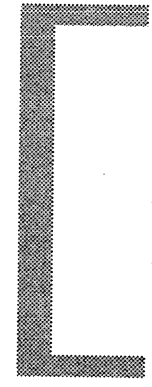

\section{Abstract}

Soligas are exposed to many government and non-government programs, their socio-economic conditions have varied from that of earlier times. In this paper the authors would like to see the changes of the role of leisure.

Introduction:

The Biligiri Rangana hills or locally known as Biligiri Rangana Betta, is located in the southeastern corner of Chamarajanagar district of Karnataka State. The name is derived from an ancient temple dedicated to the God Rangaswamy, built on a rock about 1100 meters above MSL which appears 'bili' (white), and hence "Bili-giri-Ranga" (Ranga of the white mountain).

\footnotetext{
* Women Development officer (IEDP) Nagarhole.

** Deputy Conservator of Forests, Aranya Bhavan, Mysore.

***Retired Chief Conservator of Forests, Bangalore
} 
The major tribal population found in this region is the Soligas. They are also found in the hilly and forested areas of Mahadeshwara Betta, Yelandur, Kollegal and Gundlupet taluks. A few of them reside in the forests of Hunsur, Bandipur and Kushal Nagar (Kodagu).

The word "Soliga" is spelt differently, e.g., 'Skolaga' (Thurston 1909; Aiyappan 1948), 'Sholiga' (lyer LKA 1906), and 'Soliga' (Morab 1977). Luiz speculated that the word derives from the Tamil Colai or Solai (thicket) because they dwell in the midst of thickets. Balakrishnan (1953) thought the word signified "Swamiga" for the Mahadeshwara Swamy who is their favorite deity, and got transformed to "Soliga" by corrupt usage (Morab 1977:3). Nanjundayya and lyer (1931:592599) have described that the Soligas are migrants from Annamalai Hills in Tamil Nadu, which is confirmed on the basis of their dialect. The Souvenir of Vivekananda Girijana Kalyana Kendra (1988) also gives useful information on the living conditions, health and education of Soligas.

A traditional Soliga settlement is called "Podu", which also means shifting cultivation. Thus the word Podu reflects the semi-nomadic life of the Soligas. The houses in a Podu are located on the slopes. Thick forests of the State Government surround all podus. A family selects a patch of land each year, which will be cultivated by the family members. In 1964, Government of Karnataka built 30 tiled one-room houses for Soligas in the footsteps of a small hillock called Seegebetta. Though they were reluctant to shift their residence in the beginning, after much persuasion, the government succeeded.

As the Soligas are exposed to many government and non-government programs, their socio-economic conditions have varied from that of the earlier time. So, in this paper the authors would like to see the changes of the role of leisure or importance given to the activities during leisure hours by the Soliga community.

\section{Main objectives:}

I. To study the social aspect of the leisure among Soliga tribes of B.R. Hills

2. Variation between the leisure activities of men and women

3. Variation before and after rehabilitation of the tribes

4. Their life style, living pattern, health, hygiene, habits etc., 


\section{Methodology:}

It is a sample survey from all podu's of the hilly terrain. The total number of persons interviewed is around 70 members, consisting of both male and female i.e., 7-8 from each Podu to see the variations. Data collection was performed personally by interviewing both men and women, of all age categories, filling up schedules, observing their dress pattern, housing condition, leisure activities, health and hygiene, child care etc., and involved in group discussion. The following Soliga Podu's were visited for the study purpose.

There are 9 podu's on the top of the hill: They are as follows:

\begin{tabular}{|clcc|}
\hline SLNo & \multicolumn{1}{c|}{$\begin{array}{c}\text { Name of } \\
\text { the Podu }\end{array}$} & $\begin{array}{c}\text { Number of House } \\
\text { Holds in each Podu }\end{array}$ & Total Population \\
1. & Hosa Podu & 50 & 224 \\
2. & Bangle Podu & 48 & 214 \\
3. & Muthugadagadde Podu & 44 & 236 \\
4. & Mangi Gundi Podu & 11 & 056 \\
5. & Kalyani Podu & 9 & 064 \\
6. & Seege Betta Podu & 21 & 087 \\
7. & Yerakana Gadde Podu & 59 & 233 \\
8. & K. Devara halii Podu & 25 & 100 \\
9. & Purani Podu & 77 & 340 \\
10. & Total & 344 & 1898 \\
\hline
\end{tabular}

\section{Material Culture:}

Settlement Patterns and House-types: In India, most of the tribes were largely influenced by the mainstream culture to which they were exposed. The changing scenario influenced the attitude of the tribal to a great extent. The phenomenon of "Environment Determinism", which in simple words means that environment determines the cultural stage and action, and has influenced tribal living as a whole. Deforestation changed tribal habitat and reduced tribal territory. In B.R. Hills Guruvina Gadde was a long-standing hamlet which was evicted by the forest department by burning their huts. Even to this day alternative agriculture lands have not been provided for all those who were evicted. 
The settlements, known as Podu, synonymous with shifting cultivation, are scattered. The houses are usually sited on the slope of a hill near a stream. They are built on a linear pattern, with a yard in the middle. Provision may be made for a common granary, shrine, burial ground, etc., subject to availability of land within the settlement. A specific name to a settlement follows only after some years of its establishment and stabilization. A boundary is then recognized consisting of natural features like hill ridge, bamboo grove, trees, rocks, water courses, etc., Most of them are in the interior forests, connected by foot paths and forest tracks. The number to households in a settlement varies from 5 to 26 . The families tend to be close kin-groups. Sites are generally chosen with regard to availability of forest produce, especially edible roots. Until a few years ago, they would change their settlements at regular intervals, but de to the rigidity of forest regulations, this is no longer possible. (Morab 1977: 17-23).

The houses are mostly single room huts on raised plinths, and supported by six wooden posts. The roof is sloped both sides, supported by bamboo tied with creepers. The walls and doors are formed of bamboo wattle, coated with mud plaster on both sides. The room will be provided with a hanging platform (atta) for storage of food materials. A mud wall partitions the area for kitchen from the rest of the floor area. The floor area for a family of $4-5$ members is around $8 \mathrm{ft} \times 10 \mathrm{ft}$. Only one door is usually provided, with no cross ventilation. This makes the inside smoky and uncomfortable. The limited household articles like axe, billhook, etc, are heaped in a corner. But now many of them live in one room house built by the government. They generally spend as much time as possible in the open, preferring to sleep in the yard around a fire in good weather, When crops ripen, they may erect temporary shed (Kavalu attanige) on treetops to keep watch of the wild animals.

\section{Dress and Ornaments:}

Buchanan, in 1807 wrote: "They have scarcely any clothing and sleep around a fire lying on a few plantation leaves and covering themselves with others. ("Quoted in lyer LKA Reprint 1988: IV, 592). lyer, writing a century later, found that they still. dressed very scantily (ibid. IV, 599). Nowadays, they wear cotton clothes; the men a long cloth of about 4 meters (panache) or Jotra round their waists, reaching down to the knees. Wearing a shirt is a recent trend, which is called (Kavacha). Old men cover the upper portion of the body with a long cloth instead of shirts. In the interior areas and at work, they wear only loincloth attached to their waist threads. Women wear sarees of colours that blend with the forest hues. Red and white colours are avoided for fear of attack from wild animals. They put Kumkum (bindi) or vibhuti (sacred ash) on their foreheads. Young girls are fond of putting 
on the Karalu, the red beauty spot, on their right cheek. Women generally like to dress themselves up with bangles and forest flowers.

\section{HairStyles:}

Some men tie their hair into a knot at the back of the head. Some shave most of their heads, but leave a tuft at the crown; some leave the hair to itself. Youngsters however crop them in the fashionable modes of the local caste groups. Women and girls plait the hair and let it hang behind. They do not take much care of their coiffure, they are not maintained or washed cleanly and as Morab quotes (1977:29) their heads are infested with lice.

\section{Dialect:}

The dialect of the Soliga is Soliganudi, which has a melliferous rhythm and is sonorous. Having no original script, the Kannada script is used for writing and learning purposes.

\section{Household Articles:}

They used earthen vessels for most purposes including boiling. The pot is madake and the pitcher arave. These are obtained from the market. Aluminum vessels are gradually replacing them. Brass vessels are the proud possessions of a few. For grinding ragi they use the ragi kallu or grinding stone, purchased from the stone cutters. Bamboo containers of varying sizes are used for storing milk, salt, chilies, etc., and for carrying honey. Some among them are familiar with the techniques of basketry and use a variety of them (puttee, headage, Mura, tombe, etc.) but they do not have mastery of it as a profession (Morab 1977-27-28). Slowly they have started using steel vessels for storing water, which shows the modern influence. Recent additions to the house hold articles are the radio, tape recorder in few houses and here and there one or two television.

\section{Tools and Implements:}

The Soliga obtain the tools and implements they need from the people of plains through the weekly market (sandy day), though they still use the digging stick (dasi), and the iron crow bar (hare). The axe (kodali) is the most used implement for cutting trees, felling bamboo, and all sorts of miscellaneous uses. The Katti 
(billhook) and the Kalukotlu (hoe) are the main implements used for shifting cultivation, which is sometimes known as Kalukotly cultivation for this reason (Morab 1977:35). Now they are settled cultivators using plough and other agricultural implements like the farmers.

\section{Musical Instruments:}

Tala (cymbals) is made of brass. The drum balage or Maddale or thammate is goat hide straightened across an iron rim and played by beating it with a stick. The Kombu is a brass trumpet and the kuzhalu a bamboo flute (Morab 1977:35). These symbolic instruments usage is not found frequently among the Soligas, expect during the fairs and festivals, which is conducted annually. They all sing "Goru Goruko Gorukana, Goru Goruko Gorukana".

\section{Social Organization:}

lyer (Reprint 1988: IV, 594) described four endogamous subdivision, viz., I:Urali Soliga, 2: Male Soliga, 3: Kadu Soliga and 4: Urabatti Soliga. Clan system prevailing in most tribes is a significant tribal practice; it avoids consanguinity and keeps the population genetically healthy. There are five exogamous clans or Kulam among Soligas - viz.,
A: Aluru or Haleru
B: Jungaluru or Salikaru,
C: Belloru or Bellalu
D: Suraru and
E: Tenurukutu or Teneru.

The members of Aluru and Jungaluru clans neither touch nor harm the Aluru or Jungaluru (?) trees respectively. The members of the Suraru clan adore the sun. The first three clans are said to be "brother" clans. Morab furnishes the following for the traditional clans: Teneru, Haleru, Shalikiri, Belloru, and Suraru. Only members of Shalikiri and Haleru clans are eligible to contest for the election of the headmanship of the tribal council. The other offices of pattegar, kolkar and chaluvade are assigned on hereditary basis to members of the Teneru, Belloru and Suraru respectively (Morab 1977:70-71).

As per Morab's (1977:70) opinion there is a sixth clan called Baleru Kula. This is true from our field work people talked at 6 Kula's or clans. On any important occasion like the birth or death the ritual purity cuts across five clans, but the 
Baleru clan is not affected. Earlier, this clan was considered inferior because the members had to remove the leaf plates of the people of the other five clans at important ceremonial feasts. But now this stigma is not observed. Soliga does not marry with in a clan as it is considered as brother/sister relationship. But they marry outside the clan. The lineages are called Gumpu or Budakattu. The mane devaru or the family deity is inherited through the eldest male descendants. All the members of a lineage of the same clan participate in the annual Hosa ragi hubba festival and contribute in cash or kind towards the expenses.

\section{The Tribal Council:}

The Yejaman or the tribal head post is not hereditary. Only members of the Haleru and Shalikiri clan are having the right to contest. Age, character, ability to guide and leadership are considered before electing a person. There is a Kula panchaiti or jatikoota with the yeijaman as its head. The tenure is for five years. They usually signify the election by the raising of hands, but if the contest is close, they seek divine guidance. The names of the eligible candidates are written on slips of paper and handed over to the priest of the Rangaswamy temple, who proceeds to insert them into plantain fruits, and offers them to the deity. The fruits are then handed back; each fruit is examined; the name in the first fruit showing a chit is then selected. A mudra (seal) made of silver with an engraved figure of the goddess Ranga Nayaki Amma is the insignia of office. The headman keeps it preciously in a box; at every meeting it is taken out and worshiped with vermilion and burning of incense sticks. When there is a change of incumbency, the seal is also transferred.

The Yejaman is assisted by the pattegar, kolkar, and chaluvade, drawn respectively form the Teneru, Belleru and Suraru clans. The first controls the decision process by framing the issues into specific questions. He also visits the different settlements to convey the blessings of the deities. He will visit also houses where birth or death has occurred. He carries a special stick (Kondikolu) as insignia on such visits: it is believed that it will remove the sutak (impurity). The main duty of the Kolkar is as a messenger, visiting each hamlet to announce the date, time and venue of the next meeting of the Council. All arrangements for the meeting are his responsibility; he also carries the Yejaman's seal box to the place of meeting. The Chaluvade assists both the headman and the Kolkar in arranging the meetings and keeping order, as well as to punish the offenders after judgement (Morab 1977: 84-88) 


\section{Family and Kinship:}

Father is the head of the family but the women also enjoy respect. This shows patrilineal and patrilocal in nature of family's eldest son is considered the responsible person after his father, all other children are given equal importance and care. Property if any is shared equally among male and female children equally. As ${ }^{\wedge}$ iather, mother is also equally respected and her decision is also considered in family matters.

As Evils of caste ridden Hindu Society like dowry, untouchability, are unknown in the tribal society. The tribal child develops freely in a very liberal atmosphere of a cosy tribal family. In most other caste families an atmosphere of dependency is forced on the child. Among Soligas, children who have lost their parents are not left uncared for but some neighbours do accept them without much fuss and bring them up as their own.

Compared to that of the non-tribal people, tribal attitude towards sex and interpersonal relationship is uninhibited and healthy. They have liberal sexual relationship, divorce, remarriage and widow marriage which accounts for their anxiety-free life. Nowadays they prefer the nuclear family. A man establishes a separate household after marriage, but retain contacts with the natal family, with full co-operation and participation in important rituals and ceremonies. Though the patrilineage is the structural base of Soliga society, the Mother's Brother has an important role in the life of his sisters and sister's children. He has an important role to play at the time of the life cycle rituals of his sister's children. He acts as the guardian of his sister's young children and his sisters in case of widowhood or desertion. He is held in high esteem and his advice sought in all-important matters (Morab 1977:70).

Kinship terminology is of the bifurcate merging type. Earlier, children of a sister and brother could marry but the offspring's of these unions cannot intermarry. Generation and sex are distinguished in the terminological classification. Though the terminological structure follows the bilateral cross cousin marriage rule, in actual practice, cross cousin marriages are rare, though permissible. Marriage between mother's brother's daughter, father's sister's daughter, and sister's daughter is not found among Soligas. There is a complete avoidance between a son-in law and his mother-in-law. He may speak freely, even though there is no joking relationship, with his wife's younger sister until her marriage, and is more reserved after it. $A$ woman shows utmost reverence to her husband's elder brother, even though there is no strict avoidance. 


\section{Economic Activities:}

Agriculture forms the basis of Soliga tribal culture. Their whole-hearted participation in agriculture, and their rituals connected with it proves this. Although the tribal mode of agriculture is not at all economically viable, it serves its own purpose in the tribal context. His most important cultural value of sharing becomes meaningless when he cannot grow anything to share. The ritual of offering his first harvest of God becomes the ritual of the glorious past (VGKK: 1990).

Earlier shiffing cultivation, known as Podu, or kolakotly (= hoe cultivation), was done mainly on hill slopes where the elephants may find it difficult to raid. Small patches were cleared from the forest growth by the end of January. Only the branches and leaves of the trees are chopped off and let in situ, and small sheds may be erected on the stumps to serve as watch sheds (kavalu attanige). When the maize plants are about $20 \mathrm{~cm}$ above the ground, ragi (E.corocana) is sown in the same field; usually it is women who broadcast the millet. A ritual in honour of BhumiTayi, the Earth Goddess is conducted, after which the field can be scarified by turning the sod with the hoe (Kalakotlu). Weeding is done occasionally, and watch and ward mounted against wild animals and birds.

The Soliga, when taking up fresh land for cultivation, called it Kutare, the fertile. The second year it is known as Takkily, reasonably fertile. And the third year, it was termed as Kale. Shiffing cultivation by and large is Eco-friendly. The time used for cultivation was only 4 years and later on left for forest regeneration. The avoidance of chemical fertilizer and plough cultivation also subserved this efficiency. They also grow horticultural crops like plantains in steeply sloping hillsides; vegetables are also grown near their houses.

\section{Trapping and Hunting:}

Soligas are not very expert hunters; they use traps to kill bird and wild cat by dropping heavy weights on them as soon as they touch bait. Net traps are used against the large forest squirrel. Wild pigs are caught in pit traps. A recent method, which they have obviously picked up from non-tribal, is to put firecrackers in such a way that the wild pigs will bite them and be blown up - the meat is sold to the non-tribal in part exchange for the cost of the cracker. They have no weapons developed for the hunt, but scavenge the kills of predators by driving them away with loud noises. Now as the forest area is considered to be reserve forest, hunting is prohibited. Here and there rabbits, squirrels and birds are trapped. Fish is not plentiful because the region is generally dry, but they sometimes catch fish from ponds. 


\section{Collection of Minor Forest Produce:}

Soligas economic activities also include collection of Non-timber produce (minor forest produce) like, honey berries, turmeric, tamarind, sheekakai (soapnut), medicinal roots and shoots. A tribal co-operative society (LAMPS) controlled by the government purchases all the forest produce collected by the Soligas. Honey collection is a source of livelihood and supplementary nutrition for Soligas. Honey collection plays an important role in Soliga's economy. They have two seasons, May-June and October-November. They recognize three varieties of honey, kirijenu, heijenu and tuduvejenu. The first is a produced by small bees and is believed to be medicinal, fetching a premium in the market. The tuduvejenu occurs in the hollows of trees and rocky crevices. The bulk of the honey comes from the heijenu, the ferocious rock bee found mostly on cliffs and rocks, which the Soliga's are expert in climbing. Among the minor forest produce collection, honey stands first in the list. Outside, people are barred from entering the hills in pursuit of trade in forest produce. Vivekananda Girijana Kalyana Kendra (VGKK), a voluntary organization registered under societies act in 1981, was established by a medical doctor who has been serving among Soligas since 1979. This organisation helps in purchase and processing of the products and performs sales through different marketing centers. Forest contractors and local non-tribal exploit the Soliga as cheap labour for unskilled work. The former engages them for transporting felled material from the forests, and for cutting down bamboo. The latter engage them for transplanting, fencing, weeding, etc., Under the varam system, dry cattle and goats belonging to nontribals are entrusted for grazing and upkeep until they get pregnant. The wage paid per day for male is Rs. 60/- and for female it is only 40/-. There is child labour in agriculture operation, and are paid Rs. 25/-aday.

\section{Life Cycle Rituals:}

Earlier the girl used to be segregated in a separate hut for 7 to 30 days during her first menarche. But these days it is only for 5 days. The girl's prospective husband builds the seclusion shed (gummi), or by any other male member belonging to a different clan. Maternal uncle presents her with a new sari, blouse, bangles etc. $A$ ritual called hosage hittu is observed.

Like Jenu kuruba, marriage by elopement is very common among the Soligas of B.R.Hills. This is again due to the liking towards each other and due to poverty. The union is regularised by a formal feast to the community. In arranged marriages, the boy's parents take the initiative. Elderly persons of his family visit the girl's parents; 
if the latter consent, a date is fixed for the marriage. The marriageable age of the girl is between 16-20 years and for boys, it is from 18-21 years. Dowry system does not exist. Tali tying exist and the ceremony ends with a feast. Soliga's does not have inter caste marriage and inter religion marriage. But now a day they marry with Jenu Kuruba who are considered equal to them. Divorce and remarriage are allowed for both male and female. Widow remarriage is allowed if she is young and prefers to marry.

As per Thurston (1975:VI, 382), a pregnant woman was taken to the forest and left alone by her husband a few days before delivery. If she has not returned by the third day, he carries some more food for her, but she can return only after delivery. But now the delivery takes place in once own house itself. The local women know interesting and novel ways of handling deliveries. The mother's comfort takes precedence over the convenience of the doctor. Though preference is there for male child, a female child is not neglected. Naming ceremony is performed on the fourth day for the boy and on the fifth day for the girl. Earlier they delivered about 9-12 children and they did not adopt family planning. But the recent generation has taken up family planning programme and has only 2-3 children.

The dead is usually buried. In case of unnatural deaths like, elephant stampede, accident, snakebite, consuming poison, hanging etc, the dead is cremated. The death news is sent to all the five clans' people and is awaited. Only after all the clans' men come they remove the body and the pollution lasts for 12 days. Soliga do not believe in rebirth. Earlier the rituals were very lengthy, and too many procedures were followed. Now it has reduced.

\section{Deities and worship:}

Soligas worship Jadeswamy, Madeshwara, Ketheswara, Basaveshwara, Karaiah, which is very important. They do not worship Rangaswamy as he is considered as brother-in-law. Once in a year, during January chikkajatre and during April Doddajatre (small and big) festival for Rangaswamy, the Soligas perform the prepreparation of making ready of the chariot etc. During the month of December, after harvest of new crop, Kule Man pooja is performed. They are animist who see god in everything. The officiating priest is called

Thammadi. The office passes from father to eldest son. It is considered as Devaru seve (service to God).

Female do not have any role to play in the religious activities or ceremonies. Rotti 
Habba is performed as thanks giving festival to Lord Jadeswamy by erecting pedal and offering baked flat ragi Rotti.

\section{Leisure and leisure activities and importance:}

Important festival of Soligas is Rotti Habba performed during March or April. During this festival women and men sing and dance. But such songs are remembered by the older generation and not by the youngsters, as they are influenced by the cinema songs and tape recorders. During January and April there is festival related to the temple Rangaswamy that is chikkajatre and doddajatre wherein the Soligas play an important role called bitti, where the decoration of the ratha (chariot), and preparation of the festival is by them. Hosa ragi Habba is the festival of new harvest of ragi, in october-november by individuals in the fields. Singing and dancing follow this feast all through the night. The female does Hadike that is singing and the male dances. These are some of the annual entertainment among the Soligas. Other annual festivals celebrated according to the Hindu calendar are Sankranti, Gowri and Mahanavami.

Previous to the rehabilitation, as they were whole and sole among the forest environment there were not much amusement and leisure activities among the Soligas. Hunting, food gathering, collection of honey was some of the time passes engagements. For Soliga children forest was the first school and life itself an on going process of education. Children learnt the art of honey - collection and traditional cultivation very early in life. It was education in real sense, folklore, and songs dance and religious practices were also taught during childhood. The Soliga child can identify any type of flora and fauna, which is really appreciable. Climbing trees, swimming, trekking in the forest, collection of honey, roots and tubers are the entertainment of the children. Recently the children play with round marbles (Goli), Chinni Dando (small and big sticks), cricket, preparing clay dolls, swimming in the pools and fishing, Lagori where stones are heaped one after another and ball is thrown to scatter the stones etc. female children draw squares and play with a flat stone, outside their huts. They also draw $4 \times 4$ squares (chuka Bard), keep tamarind seeds and play. Girls are fond of playing swings.

Female among the Soliga are always engaged in one or the other work like, cleaning ragi, ragi beesodu (grinding or powdering the ragi), winnowing, cooking, collection of fuelwood, fetching water for cooking and drinking purposes. Drying of the grains, grazing cattle (if available), doing wage labour, or work in their own field etc. thus she finds very little time for leisure and entertainment. They wait eagerly to takepart in the annual festivals. Soliga females are fond of cinema and whenever they find 
time, they go to Yelandur, Kollegal or Chamarajanagar to see cinema. They spend around Rs. 150-200 per month. They are also fond of cosmetics, which is recent influence that is about 6-7 years. They buy snow, powder, sticker, tape for hair tying, bangles etc.. Women have not become addicted to drinking habit. What is earned, is spent for the welfare of the family.

Men among Soligas are also equally busy during the agricultural season or rainy season. It is only during summer that they are not very busy with work, but still many of them go in search of fuel wood and other forest produce as it is a source of livelihood to them. Some of them go to coffee estates as wage labours. Their main leisure activity is sleeping and at times chit chatting in-groups. Except youngsters who are not addicted to drinking alcohol, many of the adult male members are addicts and every evening they consume alcohol. The self-help groups of women have tried enough to stop the male from drinking but it has not worked out. They purchase from Yelandur and supply among themselves. If the packets cost Rs. 15/ - the person who sells it have a margin of Rs.3-5 profit. Male members are also fond of cinema and every new change in the cinema hall, they are sure to go. Some of them also travel up to Mysore to see cinema. They spend around Rs. $300-$ 500 every month. Thus most of his earnings are spent on alcohol and cinema. Some men contribute half the earnings to his family and half is spent for his personal pleasure. They have not learnt to play cards. Some of them go for fishing, catching rabbits or squirrels for consumption.

To conclude; the process of acculturation is inevitable, but it should be guided by intrinsic factors of the given culture and not be promoted by an external agency. Any development should aim for the values and strength of tribal soci-economic condition. Government's developmental programmes often distort tribal culture, mistaking it for development. Interventions from the Government and voluntary agencies are some time inevitable to avoid exploitation of the tribes. It should be a balance of cultural non-intervention and developmental intervention, which varies form tribe to tribe. Any developmental programmes or education should be in tune to the existing knowledge so that it is further built up and does not wean away due to the onslaught of a 'modernity'. The tribal traditional knowledge should be respected and cherished. 


\section{BIBLIOGRAPHY:}

1. Gopal H; 1965, "Problems of Soligas," Social Welfare, XII(8): 20-22

2. Iyer L.K.A; (reprint 1988), The Mysore Tribes and Castes vol., Mittal Publication, Delhi 1

3. Luiz, A.A.D.1963, Tribes of Mysore, 180-186, Bangalore: Govt. Press

4. Morab S.G.; 1977, The Soliga of Biligiriranga Hills, ASI Publication

5. Morab S.G; 1982, Shifting cultivation among the Hill Soliga in Singh K.S. (Ed); Economics of Tribes and their transformation, Concept, Delhi

6. Singh K.S. (Ed): 1994, People of India, vol., Oxford University Press

7. Somasundaram, H.N. (Ed): 1990, "Soliga the Tribes and it Stride," Vivekananda Girijana Kalyana Kendra, B.R. Hills, Mysore C

8. Sheshadri M.1968, Races and Peoples of Karnataka, in Karnataka through the Ages, 111 (7071), Mysore: Government of Mysore

9. Subbayya,K.M. 1965, "Customs and Life of Soligars in Chamarajanagar," My Forest, April (43-46)

10. Thurston E. (reprint 1975), The Castes and Tribes of Southern India, vol., Cosmo Delhi 